\title{
Futbolistas, la patria o la tumba
}

\author{
Footballers, The Homeland or The Grave
}

\section{Martina Pastorino Barcia*}

\begin{abstract}
Licenciada en Educación Física por el Instituto Superior de Educación Física, Universidad de la República. Egresada de la Diplomatura en Deporte y Género de la Universidad de Buenos Aires. Maestranda en Educación Física (ISEF, Udelar). Docente del Departamento de Educación Física y Deporte, integra el Grupo de Estudios Sociales y Culturales sobre Deporte (ISEF, Udelar) y el grupo de trabajo Deporte y Sociedad de CLACSO.
\end{abstract}

\.martinapasba@gmail.com http://orcid.org/0000-00025593-3671

\section{RECIBID 0: 14.9.2021}

ACEPTAD 0: 25.11.2021

\section{Resumen}

Este trabajo discute sobre las formas en que la identidad nacional uruguaya es construida a través de los relatos del fútbol —relatos que se producen en la escena de la cultura popular de masas y que descubren algunas de las estructuras simbólicas más conservadoras-. Propongo así analizar dos publicidades dedicadas a la selección uruguaya de fútbol masculina, en el marco del Mundial de Fútbol masculino celebrado en Rusia en el 2018 y en la Copa América de fútbol masculino jugada en Brasil en el 2019. El trabajo parte de la hipótesis de que las narrativas nacionales uruguayas están basadas en un discurso machista-heroico, que dejan por fuera del fútbol a las mujeres y toda forma de masculinidad que no sea la hegemónica. De esta forma, presento una reflexión sobre las formas en que se legitiman y configuran los discursos acerca de una identidad imaginada sobre lo que es ser uruguayo(a). Finalmente expongo una propuesta de abordaje teórico-metodológico para construir nuevas narrativas que recuperen la historia y la experiencia de las mujeres jugadoras de fútbol en Uruguay.

Palabras clave: deporte, identidad nacional, Uruguay.

\section{Abstract}

This paper aims to discuss the ways in which Uruguayan national identity is constructed through football narratives. These narratives occur in the popular and mass scene, uncovering some of the most conservative symbolic cultural structures. The analysis of 
two advertisements is proposed; one dedicated to the Uruguayan men's football team in the context of men's World Cup held in Russia in 2018, and the other during the men's soccer America's Cup, held in Brazil in 2019. The assumption is made that Uruguayan national narratives are based on a macho-heroic discourse, which expels women from football, as well as any form of masculinity other than the hegemonic one. Some thought is given to the ways in which the discourses on an imagined Uruguayan identity are legitimized and configured. Finally, a theoretical-methodological approach to build new narratives which recover the history and experience of women football players in Uruguay is proposed.

Keywords: sport, national identity, Uruguay.

\section{Introducción: identidad y nación en los discursos futboleros uruguayos}

La idea de que el fútbol es el deporte nacional del Uruguay por excelencia -y que, por lo tanto, el disfrute por asistir a partidos de fútbol, practicarlo en los más diferentes ámbitos, tener conversaciones acaloradas sobre los acontecimientos recientes que rodean al fútbol nacional y mundial son partes constitutivas del ser uruguayo- se presenta como una idea inequívoca, poco cuestionada, y fundamentada en la historia nacional transmitida de generación en generación. Es parte de un imaginario colectivo que sostiene la posibilidad de compactar y explicitar los procesos identitarios de nuestro país en pocas frases, hechos y tradiciones; el fútbol, el mate, las estrofas del himno que se cantan a voz en cuello al inicio de cada partido oficial de la selección, y el patriotismo artiguista son algunas de las marcas registradas de la uruguayez.

Podemos hablar también de una serie de elementos mitoprácticos —en el sentido en que lo propone Guigou (2000) - que operan reafirmando una identidad nacional mediante mecanismos simbolizadores y significantes. La mitopraxis puede ser entendida como «una experiencia cultural productora de sentido que intenta generar continuidad de significados, a partir de aquellos significados socialmente heredados sobre la discontinuidad de la experiencia práctica de utilización de los mismos» (Mora, 2018, p. 12). Estos mecanismos de producción cultural y reafirmación identitaria, en el caso de la identidad nacional uruguaya narrada desde el fútbol, se suelen observar en la re- 
petición de mitos fundantes, en la glorificación de héroes y en el relato de hitos históricos. Y con ello, también, otra serie de proposiciones subyacentes sobre la que es llamada nuestra idiosincrasia ${ }^{1}$ uruguaya.

Afirmaciones de este tipo sobre la identidad nacional convocan, de forma no tan anónima, la idea insoslayable de que existe una forma de ser un ciudadano del Uruguay, pero, más aún, que esa forma es materializable, única, homogénea y definible por ciertos criterios dados por una idea de cultura compacta, impermeable y tangible. Una suerte de comunidad imaginada (Anderson, 1983), difamada por intereses políticos y fundada en narrativas que hablan en nombre de la nación uruguaya. Una forma de pensar, definir y caracterizar a la sociedad que podría explicarse como la respuesta a una tradición objetivista (Grimson, 2011) de las ciencias sociales, y en particular de la antropología, que ha pensado al mundo como un territorio que «alberga diferentes culturas distribuidas en el espacio, cada una con una relativa homogeneidad, sus fronteras más o menos claras y una identidad propia» (p. 20). Es decir, de asociar culturas a comunidades, identidades comunes a límites geográficos, y naciones a Estados-naciones; en síntesis, de generar amalgamas identitarias homogéneas que responden a un territorio con una bandera, un himno y una constitución propia.

Este trabajo parte de la hipótesis de que la forma de caracterizar el ser uruguayo —o, de forma indistinta, ser celeste - tiende a excluir por varios motivos a la mayoría de la población de nuestro país. Cómo o por qué se producen estas configuraciones discursivas sobre la amalgama cultural homologada con los límites territoriales y, por ende, definida como Estado-nación no es un punto que me interese desarrollar aquí. Pero sí me interesa entender por qué el deporte $-\mathrm{y}$ en particular el fútbol- es una herramienta tan efectiva para sostener estos discursos nacionalistas, así como también me interesa reflexionar sobre cómo podrían construirse otros discursos sobre la forma en que se producen las identidades en nuestro país, que reflejen con mayor complejidad y profundidad la diversidad identitaria de quienes viven en este territorio.

La propuesta es pensar sobre la cultura «imbricada en el sentido común, los hábitos, las creencias y los rituales, pero que va un poco más allá y nos permite pensar más adecuadamente las desigualdades, la historia y el poder dentro de cada cultura y entre las culturas» (Grimson, 2011, p. 43). Los estudios sociales y culturales sobre el deporte —en particular los construidos en Argentina, Brasil y posteriormente en Uruguay— han cierra una paradoja. Por un lado, la usamos corrientemente para hablar de aquello que representa a un sector social o una cultura, a un conjunto de personas; pero, por otro lado, su raíz etimológica se refiere a las palabras griegas idios y krasis, que significan 'singular' y 'temperamento' respectivamente. Es decir que, en sentido estricto, se refiere a una forma de ser individual o singular, más que colectiva, pero se utiliza a diario para referir a procesos de construcción colectiva y universal de la identidad. 
hecho un aporte fundamental este sentido, ya que ponen en el centro del debate la reflexión sobre el fenómeno deportivo en cuanto arena pública (Archetti, 1984) de lo social; un espacio privilegiado para mirar con lupa los procesos de aculturación, las relaciones de poder y las violencias de clase social, etnia y género, los megaeventos, la prensa y las configuraciones discursivas sobre las identidades/alteridades (Garriga y Levoratti, 2018).

Lo que propongo en este texto es la revisión de este ideal identitario construido alrededor de las narrativas futboleras en el Uruguay, para intentar entender las formas en que estos discursos excluyen a grandes sectores de la sociedad, con el espíritu de construir comunidad, nación, identidad. Analizaré brevemente algunos discursos massmediáticos sobre la construcción de este discurso futbolero expresados en dos publicidades, partiendo de la hipótesis de que, como productos de consumo, estos discursos masculinos y hetero-cis-normativos dejan por fuera sistemáticamente a todas las mujeres y, por supuesto, a cualquier otra forma de habitar una masculinidad que no sea la hegemónica. Al decir de Pablo Alabarces (2014): «La cultura futbolística está basada en una serie de representaciones bastante cristalizadas, casi inmodificables: por ejemplo, que es una cultura masculina y que está reservada a los hombres» (p. 17).

Si partimos de la constatación de que el fútbol ha sido históricamente un espacio privilegiado para los hombres y de los hombres - y que gran parte de nuestra identidad nacional histórica se ha construido en torno a las hazañas y narrativas del fútbol-, entonces es fácil concluir que la supuesta identidad uruguaya está sostenida en una estructura fundamentalista (Grimson, 2011) masculina, capitalina, caucásica y con un sesgo de clase (media-alta y alta) que deja por fuera un sinfín de relatos de quienes no ocupan lugares de privilegio en la sociedad. Es a partir de esta constatación que expongo al final de este trabajo una propuesta de abordaje teórico-metodológico para construir narrativas de un fútbol feminista en Uruguay, desde la experiencia del proyecto de extensión-investigación «Picaditos etnográficos», desarrollado como parte de las actividades académicas de la Universidad de la República y enmarcado en el Grupo de Estudios Sociales y Culturales sobre Deporte ${ }^{2}$ desde 2019. 


\section{La patria grande: Uruguay, fútbol y cultura popular de masas}

En el año 1832, los pocos indios charrúas que habían sobrevivido a la derrota de Artigas fueron invitados a firmar la paz, y el presidente del Uruguay, Fructuoso Rivera, les prometió que iban a recibir tierras.

Cuando los charrúas estuvieron bien comidos y bebidos y dormidos, los soldados procedieron. Los indios fueron despenados a cuchillo, para no gastar en balas, y para no perder tiempo en entierros fueron arrojados al arroyo Salsipuedes.

Fue una trampa. La historia oficial la llamó batalla. Y cada vez que los uruguayos ganamos un trofeo de fútbol celebramos el triunfo de la "garra charrúa». Eduardo Galeano, Cerrado por fútbol, 2017.

Los discursos futbolísticos nacionales se encuentran en el lenguaje cotidiano popular, en los modos de hablar, de ocupar el tiempo libre, de mirar televisión; se encuentran en las radios, los diarios, los informativos. Pueden rastrearse en las más diversas fuentes, que en la mayoría de los casos no son estatales. Como explica Alabarces (2006), en la Argentina los discursos futbolísticos suelen llenar el vacío discursivo -allí donde la tendencia neoliberal alejó al Estado de la esfera pública- que relata la construcción política de la nación. Este mismo efecto podría bien explicar también el proceso uruguayo desde el período batllista (de tendencia fuertemente estatista), y su contraste con los posteriores gobiernos de corte liberal, la dictadura cívico-militar y la vuelta a la democracia (Morales, 2013). Aunque no será un eje de este trabajo -y lo presento solo a modo de reflexión-, el cambio en los discursos nacionales y los proyectos político-gubernamentales (relacionados con la tradición partidista de nuestro país) en cuanto a su vínculo con la implementación de políticas estatales para el desarrollo del deporte, y en particular del fútbol, es un trabajo que vale la pena explorar.

Es posible entender los discursos futbolísticos como una expresión de la cultura popular de masas. Y, de esta manera, analizar cómo tienden a reflejar una especie de discurso legitimado, socialmente significado, que se va configurando por la propia historia nacional. Pero, sobre todo, por la forma en que esta historia ha sido reconstruida y relatada; que, más que expresar la maduración de un país, relata el deseo de comunidad, la necesidad de un discurso homogéneo y homogeneizador sobre qué es la patria. En este contexto, «el fútbol, permite interpretar cómo los diversos sectores de la sociedad se permeabilizan, desde una interacción de los factores políticos, económicos, sociales y culturales inmersos en la sociedad y que se inmiscuyen en lo que es la práctica 
de este deporte; se futbolizan» (Alsina y Mora, 2018, p. 3). El reforzamiento de este discurso sobre el Uruguay, futbolero y orgullosamente oriental, crece en cada megaevento deportivo en que la selección uruguaya de fútbol (masculina) participa.

La prensa escrita, radial y televisiva, las redes sociales y la publicidad orientan su atención a relatar las hazañas del fútbol que producen los 23 jugadores convocados para cada evento internacional, en nombre — nada menos - del añorado orgullo nacional. De este modo, la historia de nuestro país está marcada por los hitos de este fenómeno deportivo: los Juegos Olímpicos del 24 y el 28, el Mundial del 30, el del 50, el Mundialito del 80, las 15 Copas América ganadas, el cuarto puesto en el Mundial de 2010. Cada evento al que clasifica la selección masculina de fútbol convoca una nueva posibilidad de resaltar el heroísmo que implica disputar las preseas del fútbol mundial y ser reconocidos en todo el globo, a pesar de ser tan solo tres millones de habitantes, en un país pequeño al sur del sur. Como ejemplo de estos discursos épicos, analizo aquí dos publicidades que dan cuenta de este tipo de relato. Por un lado, la publicidad llamada «23 orientales», de una famosa cervecería nacional, Pilsen (2018), la que ha construido en sus publicidades el eslogan «Nací celeste»; por otro lado, la publicidad «Uruguay contra lo imposible» del servidor de televisión cable TCC (2015).

La publicidad «23 orientales» (Pilsen, 2018), realizada para el Mundial de Rusia 2018, narra la hazaña de los 23 jugadores uruguayos convocados por el director técnico Óscar Tabárez, haciendo un paralelismo simbólico con la historia de los 33 Orientales, que en 1825 emprendieron una cruzada para reincorporar la Banda Oriental a las Provincias Unidas del Río de la Plata, lo que devendría en la creación del Estado uruguayo independiente (aunque esto no había sido previsto inicialmente). La publicidad muestra hinchas uruguayos siguiendo la transmisión del partido en sus casas. Se van intercalando imágenes pintadas de jugadores de la selección, mientras se relata «el desembarco» de estos jugadores en la cancha: «Son 23 orientales que van a zarpar hacia Rusia y van a darlo todo. Ese es su juramento, van a desembarcar agradecidos con las glorias pasadas pero ilusionados con lograr nuevas hazañas» (Pilsen, 2018, 00:00'-00:10'). A medida que aumenta la euforia del relato, haciendo alusión a la actitud heroica y guerrera de los jugadores, las imágenes en óleo van armando el cuadro final: un conjunto de 23 jugadores que imita El juramento de los treinta y tres orientales, cuadro del pintor uruguayo Juan Manuel Blanes que homenajea el icónico momento de la historia nacional.

Aquí se evidencia el hecho irrefutable de que lo que se está uniendo es la sangre y el territorio, la nacionalidad y la guerra, y ellas con la identidad, algo propio del discurso futbolístico cotidiano (Alabarces, 2014). Esta idea acompasa a la perfección el concepto de que la defensa de la patria es motivo de sacrificio de la vida individual: «Orientales, la patria o la tumba», entona la primera estrofa del himno nacional uruguayo (que cumple su función fundamental, común a las obras de este género, de ser uno de símbolos más nacionalistas del país). Este grito bélico, esta idea de defender el país hasta la 
muerte es la misma idea constitutiva del aguante en las hinchadas de fútbol (Alabarces, 2012), de poner el cuerpo hasta el final sin importar las consecuencias, expresada en la publicidad: «Van a trancar con el alma, como aquellos heroicos que resucitaron en plena batalla y siguieron luchando» (Pilsen, 2018, 00:20'-00:24'). Lo importante es que «no se aguanta si no aparece el cuerpo soportando un daño [...]. la violencia física - no la simbólica- mantiene el sentido dominante del aguante» (Alabarces, 2012, p. 72).

En todo este discurso patriótico se yuxtapone, además -tímida pero ferozmente-, una forma concreta de habitar la masculinidad. El cuerpo masculino es el que resiste todo tipo de dolor en nombre de la gloria, diferenciando, como explica Alabarces (2012), a los machos (los que aguantan) de los no machos, que en principio son los hombres que no son adultos, o que son homosexuales, sin considerar a las mujeres porque incluso se las excluye concretamente de este simbolismo dual.

Es interesante pensar que esta hazaña patriótica — cuya tarea no menor es la de recuperar glorias pasadas (siempre refiriendo a los años dorados del fútbol nacional, el 30 y el 50) - es liderada por hombres. De hecho, quien sostiene la bandera celeste (símbolo de la selección uruguaya de fútbol) es el delantero Luis Suárez, ídolo del fútbol nacional por su trayectoria internacional. Y lo hace con el mismo gesto corporal que Juan Antonio Lavalleja, líder de los 33 orientales, en el cuadro de Juan Manuel Blanes; solo que Lavalleja sostiene la bandera de tres franjas — roja, blanca y azul- que sobre la franja blanca tiene impresa en letras negras la frase «Libertad o Muerte». Lo que quiero destacar aquí es que los referentes de la historia nacional, del heroísmo patriótico y del reconocimiento internacional, los ídolos y los modelos siempre tienden a configurarse en torno a figuras masculinas hegemónicas, lo que coincide con el hecho de que son hombres quienes han relatado la historia del fútbol y sus hazañas. Es en función de estos discursos que se construye la identidad nacional, heroica, machista y patriótica:

La identidad es un relato de una esencia que no es tal, pero que se vive como si lo fuera. No se es: se dice que se es, pero en la práctica, las conductas, las actitudes, los sentimientos, se actúa en función de esa identidad. Y en eso consiste su importancia y su eficacia. (Alabarces, 2014, p. 43)

Es este mismo discurso el que se expone en la publicidad «Uruguay contra lo imposible» (TCC, 2015), en el que lo imposible que se enfrenta es lo extranjero, los de afuera, los otros: «Nosotros jugamos con locos, matadores, pistoleros, príncipes y principitos, mariscales y hasta un chiquito gigante» ${ }^{3}$ (TCC, 2015, 00:18'-00:24'). Se vuelve a insistir en esta construcción de la identidad nacional en función de la negación de los 
otros, de acusarlos de menos aguantadores. Porque la verdadera hazaña aquí relatada es la proporción de la población uruguaya en comparación con la de la mayoría de los países mundialistas. Jugar siempre en estadios llenos de los otros, del contrincante, jugar siempre de visitante, ganar en estadios repletos de hinchas del equipo contrario, ser la minoría que festeja, dar vuelta los partidos.

Todas las historias acumulan héroes, grandes hazañas, mitos: todas las historias deportivas latinoamericanas dependen de épicas, en la victoria o en el fracaso [...] Pero esa historia local se sostiene decisivamente en la internacional: todo fútbol local prueba su trayectoria en la competencia más amplia, para poder construir un relato de independencia. (Alabarces, 2014, pp. 47-48)

Estas ideas son parte del relato mítico que circula en torno a la selección uruguaya de fútbol masculino. «Esto es Uruguay» (TCC, 2015) cierra la publicidad. De eso se trata la garra, la garra charrúa. Esta idea heredada de que nuestra cultura uruguaya moderna está impregnada de la cultura indígena que habitara nuestras tierras antes del proceso de civilización del país, de las sensibilidades de la cultura bárbara (Barrán, 1989/2017), es la que sostiene la adjetivación al seleccionado celeste. Con el mito como estandarte de que la cultura charrúa era rebelde, guerrera, resistente, fuerte, es que se nombra de esta forma a los jugadores de la selección. Es el desconocimiento de la verdadera historia, la historia del genocidio de la población charrúa en el recién definido territorio uruguayo que tuvo como protagonista al caudillo colorado general Fructuoso Rivera, la misma historia que fue relatada como batalla; es esta negación de la verdadera historia de dominación en nombre de la modernización oriental la que posibilita la construcción del discurso de la garra charrúa. Pareciera que lo que más nos enorgullece como país, esta identidad creada, está cruelmente fundada en una mentira histórica, en un mito sobre nosotros mismos. Quizá de lo que se trate aquí es de construir nuevos relatos en torno a nuestra identidad, de consolidar un nuevo discurso nacional que reconozca estas contradicciones, pero que principalmente pueda incluir la diversidad social que constituye a este pequeño pero heterogéneo país. Si hemos de hacerlo reflexionando sobre el fútbol, nos es exigido reconocer en primer lugar:

El fútbol reúne, en este cuadro, varias condiciones fundamentales: su historia [...] su vinculación con una fundación nacional-; su epicidad, su dramaticidad; su calidez, su desborde. Así se transforma en la mejor mercancía de la industria cultural. Y en particular, una mercancía drásticamente despolitizada, porque resiste a pie firme todo intento en ese sentido. Narra la nación como un repertorio de consumos, no como un conjunto de determinaciones ni estructuras; como estilos ex- 
presivos, como elecciones estéticas, como afirmaciones pasionales; pero nunca, jamás, como un conflicto de dominación que no se reduce al resultado de un partido. (Alabarces, 2006, pp. 12-13)

\title{
Relatos de mujeres en primera persona: nuevas perspectivas teórico-metodológicas para narrar los procesos identitarios del fútbol uruguayo
}

\author{
En el año 2003 se disputó el cuarto campeonato \\ mundial de fútbol femenino. \\ Al fin del torneo, las jugadoras alemanas fueron campeonas; \\ y en el año 2007 nuevamente alzaron el trofeo mundial. \\ Ellas no habían recorrido un camino de rosas. \\ Desde 1955, y hasta 1970, el fútbol había sido prohibido \\ a las mujeres alemanas. \\ La Asociación Alemana de Fútbol había explicado por qué: \\ En la lucha por la pelota, desaparece la elegancia femenina, y el cuerpo \\ y el alma sufren daños. La exhibición del cuerpo ofende el pudor. \\ Eduardo Galeano, Cerrado por fútbol, 2017.
}

Esta despolitización audaz del deporte es crucial para sostener ciertas estructuras simbólicas de dominación que son propias del mundo social y que, por supuesto, no desconocen el ámbito deportivo. En particular, como demostré, los discursos identitarios nacionales fundados en el fútbol tienden a obturar cualquier forma de participación femenina. Incluso la producción académica en torno a la historia nacional del fútbol es casi exclusivamente del fútbol que jugaron los varones. Me interesa desarrollar aquí las formas en que las estructuras de género, binarias, heteronormativas y patriarcales operan en orden social -en particular en el vinculado al campo deportivo- para luego exponer algunas reflexiones sobre cómo construir nuevas narrativas sobre el fútbol que permitan una perspectiva más amplia y diversa del fútbol local.

Para Henrietta Moore (2009) ${ }^{4}$ las relaciones de género se producen tanto como una estructura social que responde a lógicas de opresión (tales como la estructura de clase), y por ende conservan un estrecho vínculo con los modos de producción vigentes 
en cada tiempo, como a construcciones simbólicas que trascienden las formas de organización política y económica de una sociedad y se vinculan a creencias, rituales y conocimiento sobre los cuerpos. De este modo, las relaciones de género —en cuanto estructura y construcción simbólica encarnada en un lenguaje, una forma de percibir la realidad-conviven arraigadas en el deporte.

En toda disciplina deportiva en general, y el fútbol en particular, se definen formas de ser y actuar, determinantes para los deportistas hombres y para las deportistas mujeres, que constituyen, como decía antes, una identidad dominante masculina y una femenina. Para practicar cualquier disciplina deportiva, las personas deben declarar abiertamente si se definen como hombre o como mujer, pues así lo exigen las reglamentaciones deportivas (cuando hablamos de deporte de alto rendimiento). Pero esta declaración no siempre es libre, porque está definida siempre de forma biológica, basada en el dimorfismo sexual (Fausto-Sterling, 2006) y también en las expectativas sociales asociadas a un sexo u otro, que responden a identidades masculinas construidas como hegemónicas y a reforzamientos del ideal femenino: «La división social del sexo y de género se vuelve "naturaleza biológica" a partir del sistema de visión y división del mundo dominante» (Branz, 2017, p. 6). Es decir, ser varón o mujer deportista implica asumir ciertas costumbres posturales, gestos, en forma de rituales que responden a un saber ser estar en el mundo: «Hay un discurso que se encarna en el cuerpo, que se aprende. Que se logra y se alcanza. Que llega a ser auténtico cuando los otros lo reconocen» (Branz, 2007, p. 6).

En la forma en que lo define Judith Butler (2007), el género es un acto performativo, una forma de actuación, un discurso legitimador, principalmente para que el resto lo observe, lo aprecie y lo acepte; es una reafirmación constante del género que se adopta, que tiene una función de identidad individual, pero también de inteligibilidad colectiva (Butler, 2007). Podríamos decir entonces que ser futbolista implica una constante performance, constituida por gestos, posturas, un lenguaje (verbal y no verbal) y técnicas específicas de este deporte, pero también específicas de la identidad sexogenérica, que parecen definir toda una puesta en marcha de una identidad particular del fútbol. Esta performance también puede ser pensada como un acto político de resistencia, un espacio donde los cuerpos son reticentes a asumir la opresión. Es que la historia de las mujeres en el fútbol está siempre relacionada con la resistencia, con reclamar un espacio de participación, con contradecir los discursos hegemónicos del deporte. Desde la Inglaterra de principios del siglo XX, grupos de mujeres de clase media y alta se resistieron a asumir el lugar de discapacidad física, de relegación a las tareas domésticas a las que estaban destinas socialmente, producto de su posibilidad biológica de engendrar bebés (Mangan, 1989).

Si para las mujeres opera una expectativa social vinculada a las tareas domésticas, a la vida privada, a los cuidados, a lo familiar, lo delicado y sensible, para los varones 
opera una masculinidad hegemónica que tensiona todas aquellas identidades que no logren cumplir con las expectativas sociales del lugar de lo masculino: la fuerza, la virilidad, la confrontación, la procreación y, por supuesto, la heteronormatividad obligatoria. La identidad masculina tiene una performance particular en el mundo del fútbol, ${ }^{5}$ que se observa en los gestos, las posturas, el lenguaje, el reforzamiento de la sexualidad hetero y la identidad cis. Es un acto de autolegitimación constante, pero también de reafirmación del carácter masculino para que el resto aprecie o acepte, que permite ser parte de determinados grupos sociales e incluso de ocupar cierta jerarquía social respecto a grupos subalternizados o excluidos (en este caso, del fútbol). En este mismo sentido:

Se llega a ser macho «solo» si se pasa una gran parte del tiempo en el espacio que nos «hace» machos. En la lógica de la constitución de la identidad mediante «espacios reservados» hay algo que concierne a las identidades en general [...] El espacio que excluye otras identidades es un espacio «matriz» que permite la creación de las propias diferencias (La Cecla, 2004, p. 42)

Ejemplo de este modelo de exclusión sistematizada de las disidencias son los jugadores de fútbol declarados abiertamente homosexuales, cuyas trayectorias deportivas tienden a limitarse inmediatamente luego de su declaración (Gervasini, 2018). En estos casos, la homosexualidad no solamente es repudiada, sino que tiende a ser invisibilizada, para sostener un sistema hegemónico de funcionamiento cultural que desconoce los avances en derechos reclamados por los movimientos LGTBIQ+, alcanzados principalmente en las últimas décadas. El fútbol se muestra omiso, arcaico, inamovible ante estas transformaciones sociales, y sigue reproduciendo una estructura machista y patriarcal milenaria.

Lo que me interesa comenzar a esbozar aquí son algunas estrategias para la construcción de nuevas narrativas sobre el fútbol nacional, que recuperen perspectivas olvidadas, en particular la historia de las mujeres que juegan al fútbol en Uruguay. Si no hay una historia del fútbol practicado por mujeres en nuestro país no es por ausencia de jugadoras, fanáticas y luchadoras que — desafiando el statu quo- no se hayan doblegado ante la expulsión institucional del fútbol uruguayo. Es porque no hubo medios de comunicación masiva, prensa escrita, radial o televisiva que lo haya registrado, ni tampoco investigaciones que exploraran las microhistorias de mujeres que han jugado al fútbol. La falta de producción escrita (académica o de divulgación comercial) es sintomática del lugar que tiene el fútbol femenino en Uruguay. 
Esta falta de fuentes escritas nos impide una reconstrucción total de la historia del fútbol de las mujeres; sin embargo, es posible pensar en estrategias teóricas para recuperar la memoria mediante la historia oral (Skillen y Osborne, 2015) y las herramientas etnográficas (como formas de recuperar la perspectiva de las mujeres como protagonistas del relato). ${ }^{6}$ En este sentido, y asumiendo el carácter performativo del lenguaje, así como la indexicalidad de los discursos (Guber, 2001), propongo un ejercicio reflexivo para aprehender las formas de describir y construir la realidad y la historia, y con ello algunas pautas para comenzar a construir relatos sobre cómo las jugadoras han encarnado en el fútbol, cómo se han organizado para jugar y cómo perciben el mundo del fútbol que practican.

El proceso de descubrimiento antropológico resulta de un diálogo comparativo, no entre investigador y nativo como individuas, sino entre la teoría acumulada de la disciplina y la observación etnográfica que trae nuevos desafíos para ser entendida e interpretada [...] Este es un ejercicio de «extrañamiento» existencial y teórico que pasa por vivencias múltiples y por el presupuesto de la universalidad de la experiencia humana [...]. (Peirano, 2004, p. 337)

Como uno de los principales objetivos de esta reconstrucción histórica, debe considerarse la posibilidad de elaborar textos amplios y profundos que desarrollen en sus líneas formas distintas de narrar el fútbol en Uruguay, y no uno de machos y damas, sino de personas diversas que, por fuera de las identidades de género, orientación sexual o constitución corporal, puedan expresar la configuración identitaria de este deporte en nuestro país con perspectiva histórica y política. Que dé cuenta de las desigualdades estructurales que trae aparejado, pero que también pueda expresar el punto de vista de los y las protagonistas en primera persona: el placer de hacer rodar la pelota, las sensaciones del cuerpo, el dolor y el placer —el aguante como retórica, como ética y como estética (Alabarces, 2012) - y las formas en que este impacta en la vivencia futbolera. Que debata con las contradicciones propias de lo deportivo, en cuanto estructura y en cuanto agencia, con su posibilidad de dominación o de liberación. Pero principalmente que devuelva a nuestro país una historia jamás contada sobre nuestra propia identidad y la del fútbol, que reconozca en la historia el esfuerzo por construir un fútbol diferente y quizá, por qué no, aspirar a un fútbol cada vez más feminista. rramientas etnográficas para una de las primeras investigaciones sobre el fútbol femenino en Uruguay. 


\section{Reflexiones finales}

Este trabajo es apenas un ensayo que pretende empezar a instalar la idea de que es necesario construir nuevas formas de relatar la historia uruguaya y el fútbol como metonimia de la nación toda. El problema de los discursos unilaterales, de hombres que investigan, de hombres que relatan la historia de hombres que juegan, es que no representan en absoluto la diversidad que habita el territorio oriental del río Uruguay. En un ejercicio sencillo de análisis de publicidades recientes sobre la selección uruguaya de fútbol masculino, me he propuesto vislumbrar una idea, quizá no tan difícil de imaginar, sobre las representaciones identitarias que refuerza el fútbol uruguayo. Sin embargo, es necesaria una producción de conocimiento más amplia, que problematice las formas en que se construyen discursos sobre lo deportivo y, con ello, sobre la identidad nacional. En particular, que pueda hacerlo desde una perspectiva de género, con el objetivo de trascender el binarismo estructural, las brechas en el acceso, las exclusiones, el sexismo y las violencias, que tan bien calzan en el modelo deportivo moderno.

Con este objetivo en mente, es casi una obviedad decir que debe recuperarse una historia de mujeres futboleras: jugadoras, juezas, hinchas, dirigentes, técnicas, profesionales, etcétera, para visibilizar una porción de la práctica de este deporte que ha sido históricamente olvidada. Pero también es importante pensar en las intersecciones dadas por las diferentes estructuras de poder (Connell, 1995); no solo pensar en la brecha de acceso para las mujeres, sino para todas las identidades disidentes, que se apartan de los parámetros normativos de la hetero-cis-masculinidad. También en las dinámicas territoriales, como el fútbol capitalino y el fútbol del interior, en términos étnico-raciales o incluso en términos de edad: infancia, adolescencia-juventud, adultez, tercera edad. Estas yuxtaposiciones, y todas las que se encuentre posibles, permiten identificar las lógicas de poder que van organizando mecanismos de inclusión y exclusión, pero que sobre todo van esbozando los límites estéticos de la práctica corporal. ¿Cómo debe verse el fútbol? es la pregunta que hoy habita el fútbol. Quizá sea momento de preguntarnos: ¿cómo puede verse el fútbol?

\section{Referencias bibliográficas}

Alabarces, P. (2006). Fútbol y patria: El fútbol y (la invención de) las narrativas nacionales en la Argentina del siglo XX. Papeles del CEIC, (1).

Alabarces, P. (2012). Crónicas del aguante: Fútbol, violencia y política. Buenos Aires: Capital Intelectual.

Alabarces, P. (2014). Héroes, machos y patriotas. Buenos Aires: Aguilar. 
Anderson, B. (1983). Imagined communities: Reflections on the origin and spread of nationalism. Londres: Verso.

Alsina, D., y Mora, B. (2018). Yo nací cantando gol. Fútbol y murgas en Uruguay: identidades y procesos colectivos en la ciudad de San Carlos de Maldonado. Revista de Ciencias Sociales, 27(41), 7-33.

Archetti, E. P. (1984). Fútbol y ethos. Buenos Aires: FLACSO.

Barrán, J. P. (2017). Historia de la sensibilidad en el Uruguay. Montevideo: Ediciones de la Banda Oriental.

Branz, J. (2017). Masculinidades y ciencias sociales: Una relación (todavía) distante. Descentrada, 1(1), e006. Recuperado de https://www.descentrada.fahce.unlp. edu.ar/article/view/DESe006/8001.

Butler, J. (2007). El género en disputa: El feminismo y la subversión de la identidad. Buenos Aires: Paidós.

Connell, R. W. (1995). Masculinities. (2. a ed.). Berkeley: University of California Press.

Fausto-Sterling, A. (2006). Cuerpos sexuados: La política de género y la construcción de la sexualidad. Barcelona: Madrazo.

Figueiredo, T. (2019). Processo de institucionalização do futebol feminino no Uruguai. Recorde: Revista de História do Esporte, 12(2), 1-22.

Garriga, J., y Levoratti, A. (2018). Lo múltiple y lo fragmentado. Pistas para los estudios sociales del deporte. En B. Mora (coord.), Deporte y sociedad: Encontrando el futuro de los estudios sociales y culturales sobre deporte (pp. 327-332). Montevideo: Universidad de la República.

Gervasini, D. (2018). Por ese puto jugador (ensayo). En B. Mora (coord.), Deporte y sociedad: Encontrando el futuro de los estudios sociales y culturales sobre deporte (pp. 113-125). Montevideo: Universidad de la República.

Grimson, A. (2011). Los límites de la cultura. Buenos Aires: Siglo XXI.

Guber, R. (2001). La etnografía: Método, campo y reflexividad. Bogotá: Norma.

Guigou, L. N. (2000). De la religión civil: Identidad, representaciones y mito-praxis en el Uruguay. Algunos aspectos teóricos. En S. Romero (comp.), Anuario de Antropología Social y Cultural en Uruguay. Montevideo: Facultad de Humanidades y Ciencias de la Educación.

La Cecla, F. (2004) Machos: Sin ánimos de ofender. Madrid: Siglo XXI.

Mangan, J. A. (1989). The social construction of victorian femininity: Emancipation, education and exercise. En P. A. Scharagrodsky y C. R. Torres (eds.), El rostro cambiante del deporte: Perspectivas historiográficas angloparlantes 1970-2010. Buenos Aires: Prometeo.

Moore, H. (2009). Antropología y feminismo. Madrid: Cátedra. 
Mora Pereyra, B. (2018). De ir a cazar dragones te salen escamas: Estudio etnográfico sobre la producción de ethos en los clubes de la pelea. (Tesis de maestría). Universidad de la República, Montevideo.

Morales, A. (2013). Fútbol, identidad y poder 1916-1930. Montevideo: Fin de Siglo.

Pilsen [Pilsen Uruguay]. (2018, 20 de abril). 23 orientales [Archivo de video]. Youtube. Recuperado de https://www.youtube.com/watch?v=VEWvD_Aq3yA.

Peirano, M. (2004). A favor de la etnografía. En A. Grimson, G. Lins Ribeiro., y P. Semán (comps.), La antropología brasileña contemporánea: Contribuciones para un diálogo latinoamericano (pp. 323-356). Buenos Aires: Prometeo.

Skillen, F., y Osborne, C. (2015). It's good to talk: Oral history, sports history and heritage. The International Journal of the History of Sport, 32(15), 1883-1898. doi: 10.1080/09523367.2015.1132204.

TCC [UruguayPaTodoElMundo]. (2015, 30 de mayo). Uruguay contra lo imposible [Archivo de video]. Youtube. Recuperado de https://www.youtube.com/ watch?v=3oD4c-8nTBY. 